\title{
Plano Nacional de Educação, Conferência Nacional de Educação e a construção do Sistema Nacional de Educação: dilemas e proposições
}

\begin{abstract}
National Education Plan, National Education Conference and the construction of the National Education System: dilemmas and propositions
\end{abstract}

Plan Nacional de Educación, Conferencia Nacional de Educación y la construcción del Sistema Nacional de Educación: dilemas y proposiciones

\section{Luiz Fernandes Dourado'}

\section{Resumo}

O texto situa a importância da Conferência Nacional de Educação - Conae e da ação articulada da sociedade civil e política com vistas à construção de políticas nacionais, enfatizando a importância da construção de um sistema de regulamentação da educação e instituição do Sistema Nacional de Educação, bem como indicando limites e questões que permeiam tais debates.

Palavras-chave: Conae; Sistema Nacional de Educação; Plano Nacional de Educação.

\begin{abstract}
The text places the importance of National Education Conference - CONAE and the coordinated action of civil and political society towards the construction of national policies, emphasizing the importance of building a regulatory system of education and the institution of the National Educatioan System, and the article finalizes showing the limits and issues that permeate such debates.
\end{abstract}

Keywords: Conae; National Education System; National Education Plan.

\section{Resumen}

El texto pone la importancia de la Conferencia Nacional de Educación - CONAE y de la acción coordinada de la sociedad civil y política en la construcción de las políticas nacionales, evidenciando la importancia de la construcción de un sistema de regulación de la educación y la institución del Sistema Nacional de Educación, asi como indica los límites y las cuestiones que impregnan este tipo de debates.

Palabras-clave: Conae; Sistema Nacional de Educación; Plan Nacional de Educación. 
A análise das políticas direcionadas à educação básica e superior no Brasil, por meio da análise da proposição de ações, programas e estratégias articulados pelos diferentes atores governamentais implica a apreensão, no feixe dessas proposições, dos limites e possibilidades à gestão destas políticas de modo a propiciar elementos para a compreensão dos processos de regulação e financiamento, bem como os arranjos institucionais que contribuem para a materialidade das políticas de gestão e organização educacionais no Brasil como políticas de Estado.

Nessa direção, a efetivação da II Conferência Nacional de Educação (Conae) cumpre um importante papel ao conclamar a particpação da sociedade. A Conae 2014 tem por objetivos específicos, definidos pelo Fórum Nacional de Educação: 1. Acompanhar e avaliar as deliberações da Conferência Nacional de Educação/2010, verificando seu impacto e procedendo às atualizações necessárias para a elaboração da Política Nacional de Educação e 2. Avaliar a tramitação e a implementação do Plano Nacional de Educação (PNE) na articulação do Sistema Nacional de Educação (SNE) e no desenvolvimento das políticas públicas educacionais.

Por essa razão, definiu-se a seguinte temática central da II Conae "O PNE na Articulação do Sistema Nacional de Educação: Participação Popular, Cooperação Federativa e Regime de Colaboração". Para avançar na problematização e deliberação dessa temática central foram aprovados sete eixos que compõem o documento referência a saber: Eixo I - O Plano Nacional de Educação e o Sistema Nacional de Educação: organização e regulação; Eixo II - Educação e Diversidade: justiça social, inclusão e direitos humanos; Eixo III - Educação, Trabalho e Desenvolvimento Sustentável: cultura, ciência, tecnologia, saúde, meio ambiente; Eixo IV - Qualidade da Educação: democratização do acesso, permanência, avaliação, condições de participação e aprendizagem; Eixo V - Gestão Democrática, Participação Popular e Controle Social; Eixo VI - Valorização dos Profissionais da Educação: formação, remuneração, carreira e condições de trabalho; Eixo VII - Financiamento da Educação: gestão, transparência e controle social dos recursos.

Os sete eixos temáticos se articulam em sintonia às concepções e proposições aprovadas na Conae 2010 e buscam avançar no enfrentamento de questões atinentes à relação educação e federalismo, planejamento e organicidade das políticas educacionais e de seu construto por meio de participação popular tendo por objetivo a construção de políticas de Estado para a educação nacional.

Aliado a esse processo é fundamental ressaltar, após longa tramitação, a aprovação do Plano Nacional de Educação por meio da Lei 13.005/14. O PNE avança em várias metas e estratégias, algumas delas resultantes do movimento social e sindical.

\section{A Conae como espaço de discussão e políticas educacionais}

A Conae, como espaço de discussão e deliberação coletiva, avança ao ser precedida por conferências municipais/intermunicipais, estaduais e do Distrito Federal realizados ao longo do ano de 2013 e que resultaram no documento base, que incorporou as deliberações das conferências estaduais propostas ao documento referência. Estima-se que esse processo de participação resultará em esforço nacional de reflexão e deliberação das questões educacionais relativas à educação cuja convergência efetivar-se-á por meio da realização da Conferência Nacional de Educação em Brasília em novembro de 2014. Este movimento de participação e deliberação contará com a participação de diferentes atores nas conferências municipais, estaduais e distrito federal e, também, na conferência nacional.

Espera-se que a conferência ao problematizar temáticas extremamente importantes possa contribuir com deliberações que avancem no sentido de busca de maior organicidade para as políticas para a educação, sinalizando para a necessária articulação entre temáticas gerais como: regulamentação do regime de colaboração entre os entes federados, efetivação de um sistema nacional de educação, rediscussão dos marcos das políticas de financiamento (com especial relevo para as questões atinentes à política de fundos 
destacando, neste contexto, o Fundeb) e defesa da ampliação dos recursos para a educação, regulamentação da gestão democrática, sistema nacional de avaliação, sistema nacional de formação de trabalhadores em educação e temáticas específicas como implementação e consolidação de mecanismos de participação e deliberação (modalidade de escolha de dirigente escolar com ênfase na eleição direta, participação estudantil, conselhos e órgãos de deliberação coletivos, etc), políticas articuladas para os diferentes níveis e modalidades para a educação básica e superior (envolvendo questões as mais diversas tais como as formas de organização e de gestão dos sistemas e instituições educativas, dinâmicas curriculares, jornada escolar, avaliação da aprendizagem, educação e diversidade, entre outros). Todas essas temáticas tratadas tendo por norte a educação, entendida como bem público, e enfatizando o papel do Estado na garantia de educação pública e gratuita de qualidade para todos contribuirá para o avanço do cenário educativo atual, fortemente marcado por desigualdades as mais diversas.

Neste contexto é oportuno situar os desafios propostas à Conae pela comissão organizadora:

- Elaborar conceitos, diretrizes e estratégias nacionais para a efetivação do Sistema Nacional Articulado de Educação coerente com a visão sistêmica da educação que reafirma a autonomia dos entes federados e avança na organicidade do PNE;

- Integrar todos os níveis, etapas e modalidades da educação escolar numa abordagem sistêmica, com vistas a consolidar os subsistemas nacionais articulados de planejamento e gestão, de financiamento, de avaliação e de formação (inicial e continuada) dos profissionais da educação;

- Dar início ao processo de institucionalização do Fórum Nacional de Educação (FNE), convocado e instalado pelo Ministério da Educação (MEC), enquanto instância de consulta, proposição, articulação, organização e acompanhamento da política nacional de educação e de coordenação permanente das conferências nacionais de educação, no âmbito do Sistema Nacional Articulado de Educação;

- Propor reformulações necessárias para que o planejamento de ações articuladas, torne-se a estratégia de implementação do PNE no âmbito do Sistema Nacional Articulado de Educação;

- Discutir as condições para a definição de políticas educacionais que promovam a inclusão, a diversidade, dentro de uma perspectiva orgânica e republicana da educação;

- Definir parâmetros e diretrizes para contribuir com a avaliação e a qualificação do processo de ensino e aprendizagem (Brasil, 2009a).

Frente a esses desafios, destaca-se, ainda o desdobramento do documento referência em documento base, indicando concepções norteadoras direcionadas à educação nacional e dialogando com a temática central e os eixos temáticos da Conae, resultantes dos debates e deliberações nas conferências municipais, estaduais/DF. Este movimento revela a fecundidade deste processo de participação, de grande importância na arena educacional brasileira, ao deslindar novos marcos para a proposição e materialização das políticas educacionais no país, ao mesmo tempo em que tal processo, em si mesmo, constituiu-se em dinâmica formativa dos diferentes atores que participaram e construíram a referida conferência.

\section{Sistema Nacional de Educação: desafios à educação brasileira}

Considerando as mudanças vivenciadas na educação brasileira, com destaque para a aprovação e promulgação da Constituição Federal de 1988, que garantiu uma concepção ampla de educação e sua inscrição como direito social inalienável, bem como a partilha de responsabilidade entre os entes federados e a vinculação constitucional de recursos para a educação, bem como, por meio da promulgação da Lei de Diretrizes e Bases da Educação Nacional (lei 9394/96) e, mais recentemente, após mais de 3 anos de tramitação a aprovação do Plano Nacional de Educação (Lei n. 13.005, de 25 de junho de 2014), faz-se necessária a busca de organicidade das políticas por meio da efetivação de um sistema articulado e descentralizado para a educação nacional. 
OSNE se coloca como espaço político da maior relevância sobretudo se considerarmos que o cenário educacional traduz a realidade desigual e combinada do estado brasileiro, com enorme descompasso entre os diferentes níveis e modalidades de educação no que diz respeito ao acesso e à permanência com qualidade social.

A discussão histórica sobre o SNE revela concepções e desafios à sua efetivação. Tais questões envolvem as várias aobrdagens dada a discussão sobre sistema na literatura, limites do pacto federativo efetivado num Estado patrimonial, a não regulamentação do regime de colaboração, a centralidade conferida às políticas governamentais em detrimento a políticas de Estado, entre outros.

Savianni (2008) apresenta, ainda, como limites ao sistema nacional: os obstáculos econômicos: a histórica resistência à manutenção da educação pública no Brasil; os obstáculos políticos: a descontinuidade nas políticas educativas; os obstáculos filosófico-ideológicos: a resistência no nível das ideias; os obstáculos legais: a resistência no plano da atividade legislativa.

Cury (2008, p. 1204), por sua vez, sinaliza que

Um sistema de educação supõe, como definição, uma rede de órgãos, instituições escolares e estabelecimentos - fato; um ordenamento jurídico com leis de educação - norma; uma finalidade comum - valor; uma base comum - direito.

Esses quatro elementos devem coexistir como conjunto, como conjunto organizado, como conjunto organizado sob um ordenamento, como conjunto organizado sob um ordenamento com finalidade comum (valor), como conjunto organizado sob um ordenamento com finalidade comum (valor) sob a figura de um direito.

Essa coexistência, pois, supõe unidade e diversidade, essa coexistência supõe unidade e diversidade sem antinomias (ausência de incompatibilidades normativas).

Segundo o autor, no Brasil

temos um organização da educação nacional e não um sistema nacional. Nacional é a educação, na forma federativa em que comparecem competências privativas, concorrentes e comuns dos entes federativos. A atual Constituição deu continuidade à tradição advinda do Ato Adicional de 1834 e dispôs pela pluralização dos sistemas (art. 211). Esses teriam uma articulação mútua organizada por meio de uma engenharia consociativa articulada por um regime de colaboração entre todos os entes federados até como modo de se evitar a dispersão e efetivar um regime federativo na educação. Um sistema nacional de educação teria que alavancar o papel da União com uma maior presença no âmbito da educação básica e no âmbito das redes privadas dos sistemas de ensino (CURY, 2008, p. 1199).

Neste cenário, o autor (CURY, 2008, p. 1204-1205) afirma que a proposição de um sistema nacional de educação, explicitamente formulado, gera várias perguntas:

1. Pode haver uma coordenação mais clara e mais direta pela União de modo que se exerçam as funções equalizadora e redistributiva?

2. Como aprimorar as competências dos sistemas de modo que se propicie um exercício harmônico do regime de colaboração sob a coordenação mais incisiva da União?

3. 0 sistema nacional propiciaria a melhoria dos resultados em relação à aprendizagem e à socialização de valores?

Ao problematizar tais questões, Cury (2008) enfatiza a importância da promoção de um autêntico federalismo em matéria educacional, a partir da divisão de responsabilidades previstas na Carta Magna.

Por sua vez, Savianni (2008) afirma, que em relação "à construção do Sistema Nacional de Educação propriamente dito, o ponto de referência é o regime de colaboração entre a União, os Estados/Distrito Federal e os Munic ípios, estabelecido pela Constituição Federal".

A implementação do regime de colaboração representa

uma repartição das responsabilidades entre os entes federativos, todos voltados para o mesmo objetivo de prover uma educação com o mesmo padrão de qualidade a toda a população brasileira. Assim, deixam de ter sentido os argumentos contra o sistema nacional baseados no caráter federativo que pressupõe a autonomia de estados e municípios.

0 regime de colaboração é um preceito constitucional que, obviamente não fere a autonomia dos entes federativos. Mesmo porque, (...), sistema não é a unidade da identidade, mas unidade da variedade. Logo, a melhor maneira de preservar a diversidade e as peculiaridades locais não é isolá-las e considerá-las em si mesmas, secundarizando suas interrelações. Ao contrário, trata-se de articulá-las num todo coerente, como elementos que são da mesma nação, a brasileira, no interior da qual se expressam toda a sua força e significado (SAVIANI, 2008). 
Por outro lado, é necessário reconhecer, segundo Dourado (2013), que o estado brasileiro é marcado por desigualdades sociais e assimetrias entre os entes federados e, por consequência, apresenta limites no horizonte de efetivação dos direitos sociais e na capilaridade das políticas, com destaque para as políticas educacionais.

A Constitiução Federal (CF) de 1988 sinaliza novas diretrizes para os direitos sociais no País, tendo por eixo um novo pacto federativo. Ela estruturou a lógica política que sinaliza para a autonomia e o regime de colaboração, a ser regulamentado entre os entes federados: união, estados, Distrito Federal e municípios. Tais questões não se dissociam de temas como reforma tributária, novo pacto federativo, efetiva descentralização das políticas (sem perder de vista a importância da coordenação nacional da União) que tenham por eixo a regulamentação do regime de colaboração.

A CF 1988, em seu artigo 23, parágrafo único, sinaliza para a necessidade de lei complementar para a fixação de normas de cooperação entre os entes federados. De acordo, com o parágrafo único, a "Lei complementar fixará normas para a cooperação entre a União e os Estados, o Distrito Federal e os Munic ípios, tendo em vista o equilíbrio do desenvolvimento e do bem-estar em âmbito nacional". O parágrafo foi alterado e passou a ter a seguinte redação: "Leis complementares fixarão normas para a cooperação entre a União e os Estados, o Distrito Federal e os Municípios, tendo em vista o equilíbrio do desenvolvimento e do bem-estar em âmbito nacional" (Redação dada pela Emenda Constitucional n 53, de 2006).

A concepção de equilíbrio e garantias de âmbito nacional sinaliza para o esforço federativo a ser efetivado. As bases da cooperação implicam, portanto, garantir as prerrogativas de autonomia dos entes federados e, paradoxalmente, a necessidade de mecanismos regulatórios direcionados ao bem-estar nacional. Tais questões traduzem uma tensão salutar entre a ação dos entes federados, incluindo a coordenação das políticas nacionais e os processos de descentralização.

Isso revela o esforço nacional para a construção de uma sociedade cujas políticas, programas e ações tenham como convergência o bem comum por meio da garantia de direitos sociais, o que requer um federalismo cooperativo, marcado pela descentralização e por padrões e diretrizes nacionais que assegurem o direito à educação com qualidade, o que implica combater as assimetrias regionais e sociais.

Nesse cenário, algumas questões foram problematizadas por Dourado (2013): de que federalismo falamos? Como apreender suas bases constitutivas num cenário marcado por assimetrias de toda ordem, inclusive regionais, estaduais, municipais e locais? Qual o papel da União e dos governos subnacionais para o atendimento aos direitos sociais, com destaque para a educação?

Essas questões nos remetem à forma de organização territorial, ao modelo de desenvolvimento e planejamento do estado brasileiro e aos limites estruturais à sua efetivação, requerendo, entre outras, uma ampla reforma tributária que contribua para a afirmação da autonomia dos governos subnacionais e, ao mesmo tempo, não prescinda do papel de coordenação nacional da União. No campo educacional, elas têm remetido à necessidade de instituição de um SNE e de construção de planos decenais de educação como políticas de Estado, além das questões relativas ao regime de colaboração e cooperação entre os entes federados, sem negligenciar, paradoxalmente, as tensões e desafios que demarcam a definição das competências e o horizonte de suas autonomias.

Assim, entendo que a autonomia dos entes federados é ratificada, mas distingue-se de soberania, à medida que é definida nos termos da CF. Isso enseja uma reflexão ampla sobre a relação entre coordenação e autonomia, bem como a devida compreensão dos termos da CF, para a atuação dos entes federados e para a efetivação do pacto federativo brasileiro.

Essa discussão nos remete à concepção de autonomia regulada, ou seja, a autonomia dos entes federados não é sinônimo de soberania mas resultante da efetivação de bases de convergência demarcadas pela tensão entre as competências da União, sobretudo as privativas, e as competências comuns e concorrentes da união, estados, Distrito Federal e municípios. 
Tais processos, considerando as emendas à CF, demonstram a necessidade de estabelecer leis complementares que normatizem o regime de colaboração entre os entes federados. A CF, em seus artigos 23 e 211 , revigorados pela EC n 59/2009, avança no campo educacional, prevendo, inclusive, que as competências dos entes federados e a organização de seus sistemas de ensino devem se efetivar por meio de regime de colaboração.

Sobre o federalismo brasileiro há, portanto, algumas convergências, com realce para o entendimento de sua tipologia inédita, ao incluir os municípios com prerrogativas de autonomia e por caracterizar-se pelo binômio centralização/descentralização, assumindo importantes contornos na educação. Cruz (2012) sinaliza que o padrão de federalismo desenvolvido no Brasil também condiciona e influencia o setor educacional, o que é revelado pelas relações que a União estabelece com estados, Distrito Federal e municípios na gestão das políticas educacionais, embora a própria Constituição Federal defina parâmetros e responsabilidades, inclusive no financiamento da educação.

No campo educacional, a superação desses limites tem ensejado a instituição do SNE, planos decenais (nacional, estaduais/DF e municipais) com vistas a garantir maior organicidade no acesso à educação em todos os níveis, etapas e modalidades, sobretudo na garantia à educação básica obrigatória (quatro a 17 anos). Todos eles revelam um descompasso entre o marco jurídico normativo e os processos efetivos na relação entre os entes federados, o que ratifica a necessária regulamentação do regime de colaboração, sem prejuízo do estabelecimento de relações de cooperação, onde haja uma relação proporcional entre competências e capacidade financeira, o que, no caso brasileiro, ensejará reformas de ordem estrutural, incluindo a reforma tributária.

Nessa direção, o documento da Conae/2014 afirma que a organização e regulação da educação nacional deve garantir a articulação entre acesso, permanência², valorização dos profissionais, gestão democrática, padrão de qualidade, piso salarial profissional por meio dos seguintes princípios: I - igualdade de condições para 0 acesso e permanência na escola; II - liberdade de aprender, ensinar, pesquisar e divulgar o pensamento, a arte e o saber; III - pluralismo de ideias e de concepções pedagógicas, coexistência de instituições públicas e privadas de ensino; IV - gratuidade do ensino público em estabelecimentos oficiais; $V$ - valorização dos profissionais da educação escolar, garantidos, na forma da lei, planos de carreira, com ingresso exclusivamente por concurso público de provas e títulos aos das redes públicas (EC n 53/2006); VI - gestão democrática do ensino público, na forma da lei; VII - garantia de padrão de qualidade; VIII - piso salarial profissional nacional para os profissionais da educação escolar pública, nos termos de lei federal (EC n53/2006). Parágrafo único. A lei disporá sobre as categorias de trabalhadores considerados profissionais da educação básica e sobre a fixação de prazo para a elaboração ou adequação de seus planos de carreira, no âmbito da União, dos estados, do DF e dos municípios (EC n0 53/2006).

E muitas destas proposições se encontram dispostas no Plano Nacional de Educação, em maior ou menor grau.

O SNE, e na sua estruturação, a efetiva definição de formas de colaboração entre os sistemas de ensino e a fixação de normas de cooperação entre os entes federados são fundamentais para a garantia da universalização da educação obrigatória de quatro a 17 anos. Isso pressupõe um tensionamento à diferenciação que marca o sistema federativo, bem como a relação descentralização e centralização como caminho fértil para a garantia do direito à educação para todos o que se reafirma no incremento de ações interfederativas construídas de forma participativa o que caracterizaria as bases de uma concepção e lógica de gestão pautada pela interdependência.

Segundo Dourado (2013), outra definição crucial para as políticas e para o planejamento da educação no Brasil foi enfatizada na redação da EC n59/2009, ao indicar que uma lei específica estabeleceria o PNE, de duração decenal, com o objetivo de articular o SNE, em regime de colaboração entre os entes federados, definindo diretrizes, objetivos, metas e estratégias de implementação, para assegurar a manutenção e desenvolvimento do ensino em seus diversos níveis, etapas e modalidades, por meio de ações integradas dos poderes públicos das diferentes esferas federativas, incluindo o estabelecimento de meta de aplicação de recursos públicos em educação como proporção do produto interno bruto (PIB). A efetivação do SNE tem como pressuposto

2 Permanência entendida numa acepção ampla, envolvendo a garantia de aprendizagem e conclusão com sucesso pelo estudante. 
o disposto da CF/1988, segundo o qual compete privativamente à união legislar sobre diretrizes e bases da educação nacional (art. 22). A aprovação do PNE avança neste contexto, pois aprova a criação do SNE em dois anos, o que vai requerer proposições concretas sobre a sua materialidade, composição, atribuições e objetivos e, certamente, como tais processos vão interferir no campo das políticas e gestão da educação.

Nesse cenário, é fundamental avançar na problematização das questões teórico-práticas em que se colocam o regime de colaboração e a instituição do Sistema Nacional de Educação.

A compreensão das bases de instituição do SNE no documento referência da Conae 2014 é singular, pois este sistema

é entendido como expressão institucional do esforço organizado, autônomo e permanente do Estado e da sociedade, compreendendo os sistemas de ensino da União, dos estados, do Distrito Federal e dos municípios, bem como outras instituições públicas ou privadas de natureza educacional (BRASIL, 2013).

\section{Considerações finais}

Ao longo do texto situamos a importância da Conferência Nacional de Educação e da ação articulada da sociedade civil e política com vistas à construção de políticas nacionais. Nessa direção, foi enfatizado a importância da construção de um sistema de regulamentação da educação, a instituição do Sistema Nacional de Educação, bem como foram indicados limites e questões que permeiam tais debates.

Todas essas questões se articulam às condições objetivas da população, em um país historicamente demarcado por forte desigualdade social, revelada nos indicadores sociais preocupantes e que, nesse sentido, carece de amplas políticas públicas, incluindo a garantia de otimização nas políticas de acesso, permanência e gestão, com qualidade social, na educação básica e superior.

Assegurar condições políticas e de gestão para a instituição do SNE, incluindo o envolvimento e a participação da sociedade na formulação, implementação das políticas, programas, bem como a melhoria da educação nos diferentes níveis e modalidades, é fundamental e se articula ao esforço preconizado pela conferência nacional ao enfatizar a articulação entre a construção do SNE, o PNE, a gestão democrática, diversidade e a qualidade social como eixos a serem efetivamente consolidados por meio de processos amplos de participação.

Nessa direção, um dos grandes desafios à educação nacional refere-se à efetiva articulação entre os entes federados com vistas à construção de um SNE que garanta diretrizes nacionais comuns, políticas articuladas e universais. Assim, ao Sistema Nacional de Educação caberá o papel de articulador, normatizador, coordenador geral da educação nacional, por meio de um fórum nacional, visando garantir finalidades, diretrizes e estratégias educacionais comuns e, ao mesmo tempo, as especificidades próprias de cada um. Assim, o esforço de construção do SNE articula-se ao desafio de avaliação e proposição de novo PNE, como expressão de política de Estado para a área.

Por isso, a Conae cumpre um importante papel político ao problematizar a necessidade do estabelecimento de diretrizes para a instituição de um sistema nacional de educação que possibilite a ação articulada entre os entes federados, a efetivação de planejamento sistemático, que, após avaliar o conjunto de ações, programas e planos em desenvolvimento, contribua para o estabelecimento de políticas de Estado, programas e ações que garantam organicidade entre as políticas educacionais no país, envolvendo os diferentes órgãos de gestão educacional (MEC, sistemas de ensino e instituições) e, ainda, destacando a necessária mediação entre o Estado, demandas sociais e o setor produtivo, de modo a se avançar na superação do cenário educacional, historicamente demarcado pela fragmentação ou superposição de ações e programas, pela centralização das políticas de organização e gestão da educação básica no país.

Tais sinalizações remetem à busca da superação dos atuais limites estruturais à lógica político-pedagógica dos processos de proposição e materialização das políticas educacionais, fortemente marcados pela gestão centralizada. 
Nessa direção, o investimento em educação, tendo a qualidade como parâmetro de suas diretrizes, metas e ações e conferindo a essa qualidade uma dimensão sócio-histórica e, portanto, inclusiva, é outro importante desafio para o país. A busca por melhoria da qualidade da educação, neste contexto, exige medidas não só no campo do ingresso e da permanência, mas requer ações que possam reverter a situação atual, o que pressupõe, por um lado, identificar os condicionantes das políticas e gestão e, por outro, refletir sobre a construção de estratégias de mudança do quadro atual.

\section{Referências}

ABICALIL, C.A. O federalismo e o Sistema Nacional de Educação: uma oportunidade fecunda. Revista Retratos da Escola, Brasília, v.6, n.10,p.5-6, jan./jun.2012, p.21-37. Disponível em htpp//www.esforce.org.br

BRASIL. Ministério da Educação. Construindo o sistema nacional articulado de educação: o Plano Nacional de Educação, diretrizes e estratégias de ação. Documento final da CONAE 2010. Brasília, DF: MEC, 2010a. Disponível em: http://conae.mec.gov.br/images/stories/pdf/pdf/documetos/documento_final.pdf. Acesso em: março. 2013.

Presidência da República. Casa Civil. Lei 13.005/2014 que Aprova o Plano Nacional de Educação para o decênio 2014-2024 e dá outras providências. Disponível em: http://www.planalto.gov.br/ccivil_03/_ Ato20112014/2014/Lei/L13005.htm. Acesso em: julho 2014.

Ministério da Educação. Portaria n 1.407, de 14 de dezembro de 2010. Institui o Fórum Nacional de Educação - FNE. Diário Oficial da União, Brasília, DF, 16 dez. 2011.

Ministério da Educação. O PNE na articulação do sistema nacional de educação: participação popular, cooperação federativa e regime de colaboração. Documento-referência da CONAE 2014. Brasília, DF: MEC, 2012. Disponível em: <http://fne.mec.gov.br/images/pdf/documentoreferenciaconae2014versaofinal.pdf>. Acesso em: março. 2013.

CURY, C.R.J. Os desafios da Construção de um Sistema Nacional de Educação. Disponível em http://conae. mec.gov.br/images/stories/pdf/jamil_cury.pdf, acesso em 14.04.13

A questão federativa e a educação escolar. In. Educação e federalismo no Brasil: combater as desigualdades, garantir a diversidade. Brasília: UNESCO, 2010, p 149-.

CRUZ, R. E. Federalismo e educação: um pacto a se rever. Revista Retratos da Escola, Brasília, v.6, n.10, jan./jun.2012, p.65-78. Disponível em htpp//www.esforce.org.br.

DOURADO, L.F. Avaliação do Plano Nacional de Educação 2001-2009: questões estruturais e conjunturais de uma política. Educação e Sociedade, Campinas, v. 31, n. 112, p. 677-705, jul./set. 2010.

Sistema Nacional de Educação, Federalismo e os obstáculos ao direito à educação básica. Educação e Sociedade., Set 2013, vol.34, no.124, p.761-785. ISSN 0101-7330.

Avaliação do Plano Nacional de Educação 2001-2009: questões estruturais e conjunturais de uma política. Educação e Sociedade., Set 2010, vol.31, no.112, p.677-705. ISSN 0101-7330

(Org.). Plano Nacional de Educação (2011-2020): avaliação e perspectivas. 2. ed. Goiânia: UFG; Belo Horizonte: Autêntica, 2011

. Financiamento da educação no Brasil: aportes teóricos e a construção de uma rede de pesquisadores.

In. GOUVEIA, A.B.; SOUZA, A.R. Conversas sobre financiamento da educação no Brasil. Curitiba: Ed. Da UFPR, 2006, p.27-40.

; AMARAL, N.C. Financiamento e gestão da Educação e o PNE 2011-2020: avaliação e perspectivas. In. DOURADO, L.F. (Org.). Plano Nacional de Educação (2011-2020): avaliação e perspectivas. 2. ed. Goiânia: UFG; Belo Horizonte: Autêntica, 2011, P.285-315.

A conferência nacional de educação: construção democrática de políticas de estado. Disponível em 
http://conae.mec.gov.br/images/stories/pdf/texto\%20chagas\%20alterado25.03.pdf. Acesso em 20.04.13

SAVIANNI, D. Sistema de Educação: Subsídios para a Conferência Nacional de Educação. Disponível em http://conae.mec.gov.br/images/stories/pdf/conae_dermevalsaviani.pdf. Acesso em 20.04.13.

Sistema Nacional de Educação: Conceito, Papel Histórico e Obstáculos para sua construção

no Brasil. MG, Caxambú : 31ª Reunião Anual da ANPEd, 2008. Trabalho preparado por solicitação do GT-05: Estado e Política Educacional. 